\section{Mundo Rerstate} Q estudios rurales

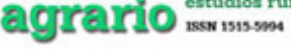

Mundo Agrario

ISSN: 1515-5994

mundoagrario@fahce.unlp.edu.ar

Universidad Nacional de La Plata

Argentina

\title{
Cazadores y pastores: agentes, mercados y derechos de propiedad en la ganadería colonial rioplatense ${ }^{*}$
}

\author{
Moraes, María Inés \\ Cazadores y pastores: agentes, mercados y derechos de propiedad en la ganadería colonial rioplatense* \\ Mundo Agrario, vol. 21, núm. 46, 2020 \\ Universidad Nacional de La Plata, Argentina \\ Disponible en: http://www.redalyc.org/articulo.oa?id=84562590001 \\ DOI: https://doi.org/10.24215/15155994e132
}

Esta obra está bajo una Licencia Creative Commons Atribución-NoComercial-Compartirlgual 4.0 Internacional. 
Dossier: Ganadería en el mundo americano: algunas reflexiones sobre tecnología, consumo e intercambio

\section{Cazadores y pastores: agentes, mercados y derechos de propiedad en la ganadería colonial rioplatense*}

Cattle hunting and cattle ranching: agents, markets and property rights in colonial Rio de la Plata

Maria Inés Moraes

Instituto de Economía, Facultad de Ciencias Económicasy

DOI: https://doi.org/10.24215/15155994e132
Redalyc: http://www.redalyc.org/articulo.oa?id=84562590001

Administración, Universidad de la República, Uruguay

imoraes@ccee.edu.uy

Recepción: 09 Marzo 2019

Aprobación: 21 Octubre 2019

\section{Resumen:}

Este trabajo discute, con base en resultados de investigación y en un esquema analítico desarrollado por el antropólogo Tim Ingold, el punto de vista que ordena la historia de la tecnología ganadera rioplatense en una secuencia lineal de etapas evolutivas. Analiza los sistemas ganaderos del Litoral rioplatense en el período colonial tardío y concluye que la tecnología ganadera del Río de la Plata desde sus etapas tempranas hasta comenzar el siglo XIX respondió al desarrollo y comportamiento de los mercados, de los diversos agentes y de los regímenes de propiedad vigentes en las diversas comunidades del territorio.

Palabras Clave: Río de la Plata colonial, Historia de la ganadería, Tecnología ganadera, Uruguay.

\section{Abstract:}

This paper discusses the viewpoint that orders the history of Rio de la Plata's cattle-ranching into a linear sequence of progressive technical change. Based upon an analytical framework developed by anthropologist Tim Ingold, it analyzes the livestock systems of the Rio de la Plata coast during the late colonial period and concludes that livestock technology in the Rio de la Plata from its early stages until the beginning of the 19th century was driven by the interplay of markets, agents and property rights across the diverse agrarian landscapes of the region.

KEYwORDs: Colonial Rio de la Plata, Cattle-ranching history, Technical change in animal husbandry, Uruguay.

\section{INTRODUCCIÓN}

Durante mucho tiempo la historiografía del Río de la Plata ofreció una narrativa sobre los orígenes y la historia de la economía ganadera regional ordenada en etapas evolutivas (Ruano Fournier, 1936; Bernhard, 1958; Barrios Pintos, 1967; Coni, 1979). De acuerdo con esa narrativa, los europeos trajeron al Río de la Plata ciertas especies animales de cría, como bovinos, bueyes, vacas, caballos, cerdos y ovejas, para emplearlos como alimentos en algunos casos, como arma de guerra en otros y como fuerza de tracción siempre que fuera posible. Siendo tan exiguos los contingentes humanos que los sometían a rodeo, muy pronto los equinos y bovinos escaparon al control doméstico, y adaptados rápidamente al ecosistema de praderas, produjeron abundante descendencia que no conocía el contacto con el hombre. En el caso de los bovinos, este fenómeno dio lugar a la formación de extensas manadas de animales cerriles denominados "cimarrones", cuya memoria genética ya había borrado la domesticación. Según este relato, surgió así la primera etapa en la historia de la ganadería rioplatense, cuando los colonos desarrollaron la práctica de organizar excursiones de caza de bovinos cimarrones con el único fin de extraerles la piel para convertirla en cuero, sin aprovechar la carne y apenas aprovechando la grasa animal. De modo generalizado, la historiografía consideró que estas excusiones, frecuentemente llamadas “vaquerías”, definían la etapa más antigua, y también la más atrasada desde el punto de vista tecnológico, en la historia de la ganadería rioplatense (Ruano Fournier, 1936; Barrios Pintos, 1967; Coni, 1979; Giberti, 1985). 
En efecto, se consideraba que las vaquerías eran una actividad de caza, puramente extractiva y depredadora del stock animal, que no movilizaba más destrezas que las de cualquier gaucho temerario acostumbrado a galopar sin pausa por las praderas desiertas. La versión establecida consigna que los ganados cimarrones fueron agotándose progresivamente por efecto de su explotación sin cuidado, y a medida que crecía el tamaño de las poblaciones de los diversos e inseguros ejes colonizadores sobre la cuenca platense, se desarrolló una ganadería de cría, que constituye una segunda etapa, más avanzada, en la historia del cambio técnico de la economía ganadera rioplatense. Así surgieron establecimientos rurales especializados en criar y engordar bovinos domesticados, destinados a la producción de carne para el consumo de pueblos y ciudades. En términos generales los historiadores consideraron que esta ganadería representaba un paso adelante desde el punto de vista tecnológico, y por lo tanto productivo, con respecto a las "vaquerías" para hacer cueros (Pivel Devoto, 1952; Sala, Rodríguez y de la Torre, 1967b; Giberti, 1985). También consideraban que era un paso adelante desde el punto de vista social, porque generaba asentamientos humanos estables, si bien de tamaño reducido. En sus etapas más avanzadas esta ganadería de cría y engorde produjo, desde finales del siglo XVIII, no sólo carne fresca para las ciudades cercanas sino también carne salada que se exportaba a largas distancias, para abastecer economías esclavistas en Antillas y Brasil (Montoya, 1984).

Por último, el relato concluye con la afirmación de que en la segunda mitad del siglo XIX los sistemas ganaderos bovinos del Río de la Plata iniciaron lo que sería su etapa culminante desde el punto de vista tecnológico. Después de 1860 los diversos sistemas ganaderos rioplatenses incorporaron técnicas de mejoramiento genético de los animales, modificaron las bases alimenticias de los animales mediante nuevas técnicas de manejo del pasto en algunas regiones y mediante la introducción de cultivos forrajeros en otras, y mejoraron los rendimientos físicos tanto de ovinos como de bovinos (Giberti, 1986; Bernard, 1956; Barrán y Nahúm, 1967; Millot y Bertino, 1991). Gracias al desarrollo que alcanzó la producción animal entonces, Argentina y Uruguay se convirtieron en destacados exportadores de lanas en los mercados mundiales y vieron nacer una poderosa industria de carnes enfriadas que cimentó la riqueza de los emporios ganaderos rioplatenses y de sus clases terratenientes entre 1870 y 1914 (Barrán y Nahum, 1978; Giberti, 1985; CortésConde, 1979).

El relato presentado contrapone esencialmente la caza a la domesticación de animales, y siguiendo una tradición intelectual del siglo XIX, presenta la domesticación de animales como un avance tecnológico con respecto a "etapas primitivas" de aprovechamiento de los animales silvestres, genéricamente englobadas en el concepto de "caza". Así, la historiografía durante mucho tiempo asoció la explotación de animales silvestres con prácticas económicas propias de comunidades anteriores al Neolítico, es decir a la domesticación deliberada de plantas y animales, y por lo tanto carentes de un conocimiento propiamente tecnológico.

Esta contraposición entre sistemas ganaderos basados en animales silvestres y sistemas basados en animales domesticados fue controvertida por la antropología del último cuarto del siglo XX (Galaty, 2015). En este artículo se apelará a algunas ideas del antropólogo Tim Ingold, quien a partir del estudio de comunidades contemporáneas de pastores y cazadores, cuestionó la noción de que la diferencia entre pueblos pastores y pueblos cazadores expresa diferencias en su desarrollo tecnológico. En sus trabajos con pueblos cazadores contemporáneos, Ingold mostró que sus prácticas no expresan un desconocimiento de las técnicas de domesticación ni un supuesto desinterés “cultural" por adquirirlas. En cambio, son el resultado de circunstancias económicas y relaciones sociales, expresadas en unos mercados y unos derechos de propiedad, que les dan lógica y persistencia (Ingold, 1980 y 1986).

Ingold trazó un paralelo entre las actividades de los pueblos cazadores y las actividades que llevan a cabo los predadores no humanos para proveerse de alimentos. Observó que, a diferencia de los animales predadores, los humanos no están en contacto permanente con su presa, sino que deben salir deliberadamente a su encuentro, en unos territorios donde, además, desarrollan una compleja trama de relaciones de habitación con los recursos naturales (la tierra, el agua, los bosques). En consecuencia, cuando las comunidades cazadoras salen a la busca de su presa tratan no sólo de satisfacer sus necesidades inmediatas, sino también de acopiarse 
para satisfacer necesidades futuras. A partir de sus estudios sobre la caza de renos entre los pueblos de las estepas árticas y subárticas, subrayó el carácter oportunista de las expediciones, que no les permite a sus practicantes ser selectivos. Así, los cazadores durante las expediciones cazan cuantos ejemplares puedan, incluidas hembras y especímenes de corta edad, para obtener el mayor provecho de la excursión. Al respecto, el autor observó que cuando el objeto de la expedición es la piel de los animales (como era en las "vaquerías" rioplatenses), los cazadores dejan la carne tirada y sin aprovechar, lo que da lugar a la formación de un nicho ecológico apto para el desarrollo de especies de perros carroñeros (tal como denunciaron numerosos cronistas del siglo XVIII en el Río de la Plata).

Sin embargo, el autor enfatizó que esas prácticas no son el resultado ni de la ignorancia ni del descuido de estos pueblos, sino la expresión de un conjunto de conocimientos adaptados de manera muy precisa a los fines y a las restricciones de las expediciones. Afirmó que no son las técnicas de caza por sí mismas las que conducen a la extinción de las especies cazadas, ya que los pueblos cazadores son muy cuidadosos a la hora de evitar poner en riesgo una fuente principal de recursos, y agregó que, por el contrario, cuando ocurren situaciones de sobreexplotación de los animales, deben buscarse sus causas en modificaciones de las condiciones económicas y sociales que les dan marco.

Finalmente, Ingold concluyó que la diferencia sustancial entre las sociedades de cazadores y las de pastores no concierne al hecho de que los animales estén o no domesticados, sino al tipo de derechos de propiedad que (re)conocen esos pueblos: ambos tipos de comunidad conocen la domesticación de animales, pero mientras las comunidades pastoras reconocen derechos de propiedad sobre los animales vivos, las comunidades cazadoras reconocen derechos de propiedad sobre los animales muertos. Así, el cambio de un modo a otro de explotación ganadera no ocurre porque aparezcan o se copien unos métodos de domesticación y unas técnicas de manejo ganadero hasta entonces desconocidos, sino por cambios en las condiciones económico-sociales y medioambientales que valorizan los animales cazados por sobre los animales criados, o viceversa.

En los apartados que siguen se apelará a estas ideas para controvertir el relato tradicional sobre el "atraso" de los sistemas ganaderos asociados a la extracción del cuero y la "modernidad” de la ganadería de cría. Este trabajo propone que la historia de la tecnología ganadera en las praderas rioplatenses no es una historia lineal de etapas evolutivas, en la que, a partir de una etapa inicial caracterizada por la caza de animales silvestres, las comunidades humanas de los diversos paisajes agrarios del Río de la Plata consiguieron a ritmo desigual incorporar las prácticas de la cría, en un proceso progresivo que condujo de la caza a la cría y engorde de animales bovinos. Por el contrario, afirma que los sistemas ganaderos rioplatenses del siglo XVIII y hasta las primeras décadas del siglo XIX ofrecen un caso de convivencia de prácticas cazadoras, arreadoras y criadoras sobre una misma especie animal. Esta convivencia puede explicarse por la confluencia -durante buena parte del período colonial - de dos circunstancias: por un lado, la disponibilidad de recursos naturales y mercados suficientes para diversos productos derivados del ganado bovino, y por otro, las características de los derechos de propiedad vigentes.

\section{Los Pastizales del Río de la Plata: un ecosistema, diversos paisajes}

Los pastizales del Río de la Plata constituyen un vasto ecosistema de aproximadamente $750.000 \mathrm{~km}^{2}$, ubicado en la porción Este de América del Sur entre los $28^{\circ}$ y $38^{\circ}$ S. a lo largo de una extensa llanura que cubre el centro- este de la Argentina, todo el territorio uruguayo y el Sur de Brasil (Soriano, 1991) (ver figura 2). Se caracteriza por la ausencia generalizada de árboles, un relieve llano o suavemente ondulado y el predominio de una vegetación pratense extraordinariamente rica, donde conviven cerca de 1100 especies diferentes de pastos. Desde la incorporación del territorio a la colonización europea, los pastizales del Río de la Plata han sido asiento de actividades agrícolas y de pastoreo que adoptaron modalidades cambiantes con el paso de los siglos. 
La excepcional aptitud natural que el ecosistema en su conjunto presenta para el pastoreo de animales a campo abierto creó las condiciones para el surgimiento y desarrollo de diversos sistemas ganaderos durante los últimos 400 años.

Durante los siglos XVII y XVIII los sistemas productivos allí organizados presentaron tempranamente un rubro ganadero cuya producción llegaba tanto al Potosí como a Minas Gerais. Un historiador del período colonial reconoció en estos territorios una cuenca ganadera de América meridional (Vázquez-Franco, 1986).

Aunque todo el conjunto se asienta sobre una vasta llanura cubierta de pastos, existen diferencias en el lecho rocoso del suelo, en el tipo de suelo, en el relieve y en su capacidad de drenaje. Estos factores influyen sobre la vegetación pratense y crean diferencias sutiles pero importantes dentro del ecosistema. Esta diversidad de morfologías que presenta la pradera rioplatense en lo tocante a suelo, clima, drenaje y tipo de pastos habilitó la formación de paisajes agrarios también diversos - aunque integrados entre sí - en el vasto territorio de la pradera regional (Soriano, 1991: 367). En otras palabras, el ecosistema de pastizales rioplatenses se presta para el surgimiento de sistemas agrícolas y ganaderos diversos e interconectados, fenómeno que se expresó desde el siglo XVII en adelante por medio de múltiples conexiones e intercambios de agentes y recursos de los diversos paisajes agrarios surgidos en él, de formas a veces cooperativas y muchas veces competitivas. Esta situación de integración "natural" fue posible no sólo en las etapas tempranas del proceso de ocupación del territorio y en ausencia de derechos privados de propiedad; por el contrario, persistió de manera modificada aún después de que dicho proceso hubiera dado lugar no sólo a la propiedad privada de la tierra y los ganados, sino incluso a los Estados nacionales, con sus respectivas fronteras. Así, por ejemplo, todavía en la primera mitad del siglo XX era muy común que los ganaderos brasileños poseyeran estancias a ambos lados de la frontera con Uruguay, usando los campos del lado brasileño (donde el relieve y el clima protegen mejor los ganados de menos de un año) como áreas de cría, y las áreas del lado uruguayo como área de engorde (Menegat, 2016). 


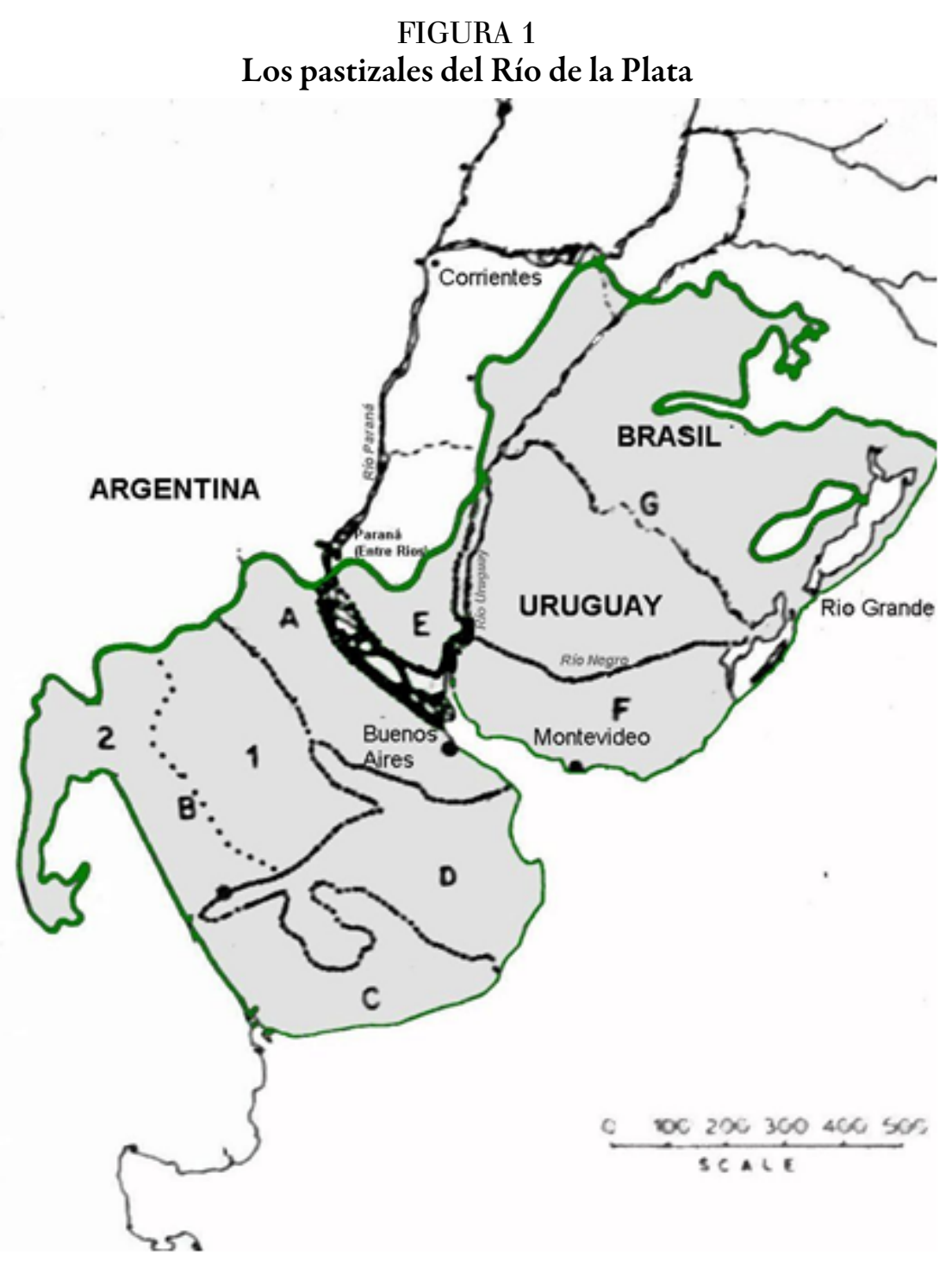

Fuente: Soriano (1991, p. 368)

En otros trabajos analicé tres espacios económicos de la porción española de la cuenca platense en la segunda mitad del siglo XVIII, cuya localización aproximada se representa de manera esquemática en la figura 1 (Moraes, 2011,2015a). Conviene advertir que los espacios allí representados no fueron los únicos protagonistas de la geografía histórica y económica de la cuenca platense, y en particular, debe aclararse que, por razones de espacio, en este trabajo no se hacen referencias más que laterales a un cuarto espacio de gran importancia para el análisis histórico: el representado por el avance portugués al sur de Viâmao hasta Río Pardo. En cada uno de los espacios de la figura 1 se desarrollaron paisajes agrarios que, por diversas razones que no cabe explicar aquí, dieron forma y figura a los sistemas agrícolas y ganaderos en los territorios del ecosistema de pastizales del Río de la Plata durante el siglo XVIII (Moraes, 2011, 2015a). La noción de paisaje agrario se usa aquí como un instrumento de análisis que no conviene asociar a un dibujo estático en un papel. En lo concreto, cada uno de estos paisajes agrarios constituyeron mundos rurales con unos agentes, unos mercados, unas instituciones, unas prácticas tecnológicas y unos territorios que experimentaron cambios a lo largo de su historia.

El más septentrional de estos paisajes agrarios pertenecía al espacio misionero. Nació y se desarrolló entre la segunda mitad del siglo XVII y la primera mitad del siglo XVIII como el segmento ganadero de los pueblos misioneros jesuitas localizados entre el Alto Paraná y el Alto Uruguay. Orientado a la producción de carne 
para el consumo de los habitantes de los pueblos fundados por los jesuitas en el corazón de la América meridional, nació con el objetivo de abastecer de carne a una población que constituía el mayor conglomerado demográfico de la región platense hasta casi el final del siglo XVIII. Estaba formado por campos de pastoreo (“estancias") de propiedad comunal localizados al sur del río Ibicuy, pertenecientes a los distintos pueblos del complejo misionero. Los pueblos llamados de Yapeyú y San Miguel poseían las estancias más grandes, pero no menos de cuatro pueblos misioneros adicionales tuvieron sus propias estancias comunales. El territorio de este paisaje, que en otro trabajo he llamado "pastoril-misionero" (Moraes, 2008), ocupaba un extenso territorio cuyo tamaño experimentó variaciones a lo largo de sus casi dos siglos de existencia, pero que en su mejor momento rondaba los $100.000 \mathrm{~km}^{2}$.

El paisaje pastoril misionero estaba integrado al vasto espacio de la economía misionera, que incluía diversos paisajes agrarios desarrollados para aprovechar recursos ofrecidos por diferentes ecosistemas. Así, en el espacio misionero se producían alimentos para el autoconsumo de los pueblos misioneros, algodón para la fabricación de lienzo que se exportaba a diversas ciudades españolas de la región platense, yerba que también era vendida fuera del espacio misionero, y maderas duras empleadas en la fabricación de barcos y viviendas. En conjunto, este espacio era la base de sustentación económica de los treinta pueblos misioneros que en la mitad del siglo XVIII llegaron a sumar más de 100.000 habitantes (Moraes, 2011).

Bastante hacia el sur, en la campaña de Buenos Aires surgió desde el siglo XVI un paisaje agrario que en la mitad del siglo XVIII poseía una rica variedad de unidades productivas de orientación agrícola y ganadera localizados en el área pampeana, sobre una estrecha franja de tierras contiguas a la costa platense y a la desembocadura del Paraná (Garavaglia, 1999; Mayo, 2004). Del otro lado del Río de la Plata, ya fuera de la pampa, una segunda campaña de Buenos Aires se desplegaba en torno a las zonas de Víboras, Espinillos, Las Vacas y, después de 1777, la antigua plaza de Colonia (Moraes, 2008 ). La producción agrícola del paisaje bonaerense, en su conjunto, se destinaba a alimentar los centros urbanos, pero su producción ganadera, además de abastecer de carne a las ciudades del lugar, estuvo siempre conectada a espacios extra-locales, ya sea el Potosí o los mercados atlánticos. Así, el paisaje agrario bonaerense estaba íntimamente vinculado al mercado interno colonial pero también estaba expuesto a los avatares del comercio de ultramar. 
FIGURA 2

Espacios económicos del Litoral rioplatense colonial, siglo XVIII

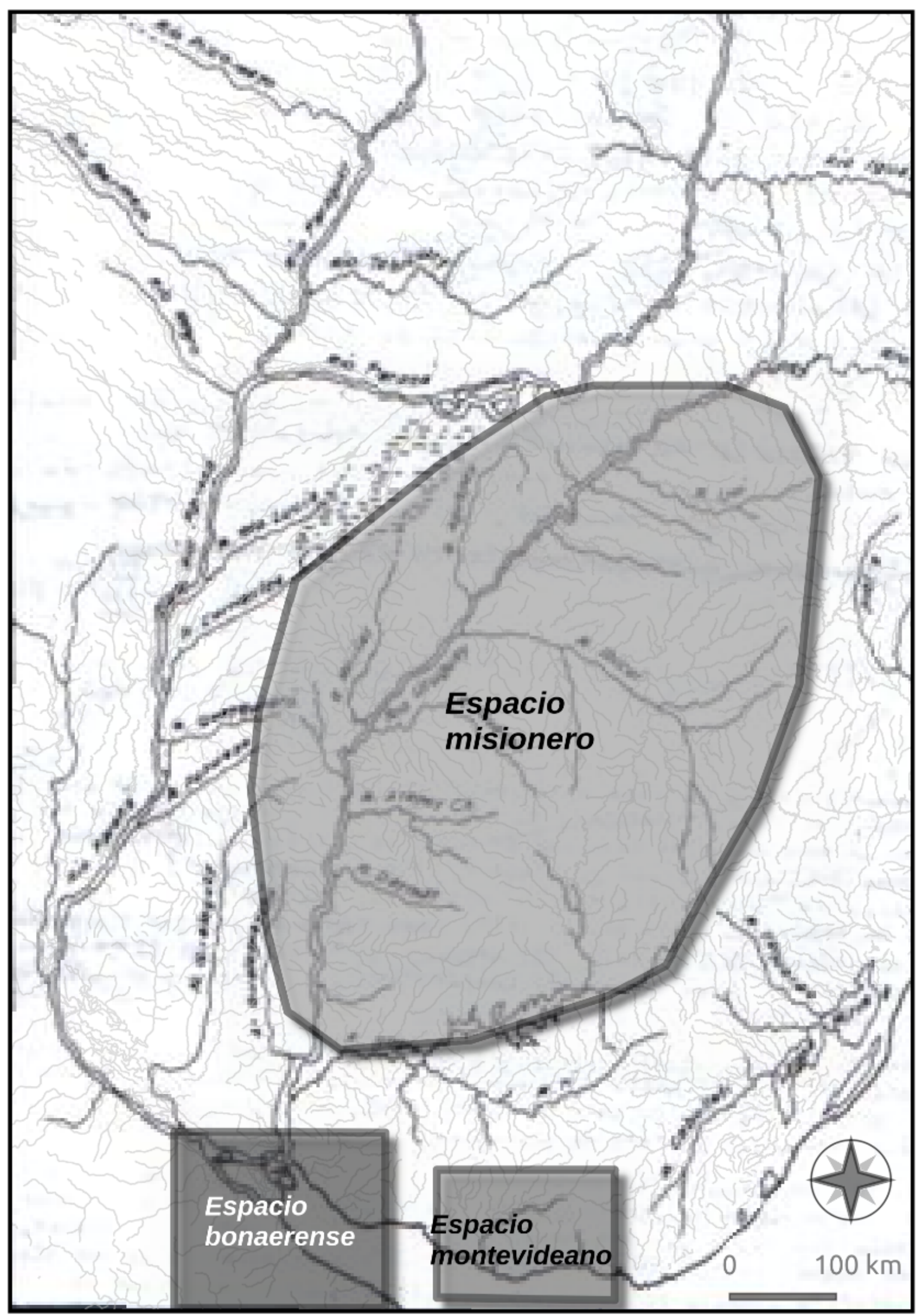




\begin{abstract}
Fuentes: La representación cartográfica del estuario platense está tomada de Maeder y Gutiérrez (1992). La representación de los espacios misionero, bonaerense y montevideano es aproximada; referencias más precisas a los límites de cada uno de ellos en diversos momentos de la segunda mitad del siglo XVIII pueden verse en Garavaglia (1999) para el caso de Buenos Aires, Maeder (1992) para el caso del espacio misionero y Pollero y Sagaseta (2015) para el caso de Montevideo. La autora agradece al geógrafo uruguayo Nicolás Frank la realización de esta imagen.
\end{abstract}

El más oriental de estos paisajes surgió en el espacio montevideano, una sub-región económica donde, como en Buenos Aires, se conjugaban actividades portuarias con funciones defensivas. Un paisaje agrario se fue conformando en la jurisdicción de Montevideo, a partir de su tardía fundación en la década de 1720, con la modesta vocación de dar sustento a la pequeña ciudad-fuerte. Genéticamente emparentada con la de Buenos Aires, la economía agraria montevideana heredó de la primera su morfología de chacras y estancias basadas en derechos individuales de propiedad sobre la tierra y el ganado, así como unos sistemas de cría de animales y de agricultura de cereales para el consumo interno muy similares a los de su vecina (Moraes, 2011).

\title{
2. CAZAR PARA AMANSAR Y CRIAR: EL SISTEMA GANADERO MISIONERO
}

Desde su creación en la mitad del siglo XVII hasta el comienzo del siglo XIX, las estancias misioneras se basaban en la recogida de ganado cimarrón para someterlos a un proceso de amansamiento y recría.

La formación de las estancias de Yapeyú se hizo con ganados cimarrones de toda el área de pradera circundante. En la mitad del siglo XVIII existían numerosos reservorios de ganados cerriles en los territorios al norte del Río de la Plata, porque las praderas estaban intactas en su potencial nutritivo y las poblaciones humanas estaban muy dispersas en el territorio, sin llegar a controlarlo. Por lo tanto, cuando los jesuitas que habían colonizado el territorio con sus misiones decidieron, a fines del siglo XVII, crear estancias para engordar ganado, lo primero que hicieron fue salir al campo a recoger ganados silvestre. Algunas fuentes llaman "vaquerías" a estas recogidas.

El jesuita Cardiel, quien estuvo a cargo del pueblo de Yapeyú hacia la década de 1740, narró con precisión la técnica desarrollada para recoger ganado cimarrón:

(...) Van 40 o 50 indios con 5 caballos cada uno. Ponen en alto una pequeña manada de bueyes y vacas mansas, para ser vistas de las cerriles, y a competente distancia las rodean o acorralan treinta o cuarenta hombres para su guarda. Los demás van a traer allí las más cercanas, que vienen corriendo como cerriles; y viendo las de su especie, dándoles ancha puerta los del corral, se entreveran con ellas. Vuelven por otras: y del mismo modo las van entreverando, hasta que no hay más en aquella cercanía. Júntanse todos los jinetes y yendo uno o dos delante por guías, cerrando los demás todo lo que cogieron, van conduciéndolo adonde hay más, teniendo cuidado de no acercarse mucho: que si se acercan, y las estrechan, suelen [los ganados cimarrones] romper por la rueda y esparramarse. En el segundo paraje, hacen lo propio. Llegada la noche, rodean su ganado y hacen fuego por todas partes y de este modo en medio de la campaña está quieto. Si no hacen fuego, [los cimarrones] rompen y se van por medio de los jinetes. De este modo, 50 indios, en dos meses o tres, suelen coger y traer a su pueblo de distancia de cien leguas, cinco mil o seis mil vacas. De los caballos mueren algunos, ya a cornadas de los toros, que arremeten a cornadas a caballo y jinete; ya del mucho cansancio, y mal trato que les da el indio. Los demás quedan tales que no pueden servir en todo el año; y se ponen en lozanos pastos a convalecer y engordar. Todo eso cuesta esta faena (Cardiel, 2002).

Del relato se destaca la destreza desplegada por parte de un grupo de 40 o 50 humanos para arrear algunos miles de bovinos silvestres. Estas expediciones de caza no eran actividades contrapuestas a la domesticación sino todo lo contrario: servían para iniciar la formación de planteles de animales mansos. Cardiel explica claramente el proceso de "amanse" de los bovinos cerriles mediante la técnica del rodeo:

(...) El modo de hacer las vacas de cimarronas mansas, es éste: después de cogidas del modo dicho, seponen en la estancia del pueblo cerrada por todas partes con arroyos, pantanos o zanjas hechas a mano, aunque ninguna está tan cerrada por la incuria de los indios, que no tenga muchas partes por donde salirse. Alli las dividen en tropas de a cinco mil o seis mil; y colocan cada tropa en sitio determinado algo cerrado, para que no se junten con otra tropa. Y a esto llaman RODEO. Juntan este rodeo a los principios cada dia para que no se esparzan, que forcejean a ello, para volverse por donde vinieron y para que se hagan a aquel paraje; $y$ porque este tan frecuente rodeo no les da tiempo para pacer a gusto; después de algunas semanas juntan el rodeo sólo dos veces a 
la semana y las tienen en él en alguna loma algo alta dos o tres horas, rodeándolas por todas partes, y en partes las meten y hacen el rodeo en un grande corral de palos. (Cardiel, 2002: 84-85).

Las actividades de cría en las estancias misioneras alcanzaron bajo la administración jesuita un desarrollo tecnológico considerable. La unidad productiva mínima del espacio pastoril misionero era el puesto de estancia. Un pormenorizado estudio de la estancia de Yapeyú en la segunda mitad del siglo XVIII mostró que los puestos estaban especializados en diferentes especies animales: unos en la cría de mulas, otros en la de vacunos y otros en la de ovinos (Garavaglia, 1975). Un estudio arqueológico sobre puestos de la estancia de San Miguel identificó que tenían un núcleo arquitectónico formado por una plaza, una capilla, una era, un pozo de agua y viviendas. En algunos casos se encontró también una cantera de donde se extraían los materiales para hacer todas estas instalaciones, y en uno de lospuestos se halló un silo semi-subterráneo, donde se encontraron restos de losa vidriada, cerámica guaraní, semillas de trigo, cebada, centeno, zapallo y algunas frutas, entre ellas el durazno. La construcción más importante de los puestos misioneros eran los corrales, grandes formas rectangulares o circulares delimitadas por muros de piedra, de hasta 3 metros de altura, ubicados a distancias variables del núcleo central. Se encontraron corrales grandes alejados del núcleo, de hasta 150 metros de diámetro, posiblemente destinados al amanse de cimarrones, y otros más pequeños, posiblemente destinados al encierro de los animales de trabajo y de aquellos ya amansados que se pensaba enviar al pueblo de destino. Alguno de estos puestos tenía también una suerte de carnicería para la faena del ganado y un horno de barro para la cocción de tejas y ladrillos (La Salvia, 1988).

Esta evidencia sugiere que dentro de estos puestos se realizaban numerosas tareas: obviamente las principales, y las que dan sentido al puesto, son las relativas al amanse, recogida y cuidado de los bovinos. En los puestos más grandes se desarrollaban de forma regular tareas agrícolas y la fabricación de ladrillos y de tejas. Se conocen pocas descripciones del trabajo en las estancias misioneras. Antonio Sepp, quien pasó en Yapeyú un largo período entre los últimos años del siglo XVII y los primeros del siguiente como sacerdote, redactó unas Advertencias sobre el gobierno económico de los pueblos, "a petición de algunos Padres nuevos para servirlos", que permiten reconocer, además de las actividades relativas a la cría de bovinos, la cría de mulas y de ovinos, incluyendo la esquila de estos animales (Sepp, 1985).

El trabajo en los puestos ganaderos era ejercido por grupos familiares de indios misioneros que, por turnos, pasaban a ocuparse de las faenas en las estancias. Su trabajo era rigurosamente supervisado por los jesuitas:

(...) Lo que hace el Cura es esto. Visita la estancia una vez al año, si está muy lejos (algunas distan 30 o 40 leguas del pueblo); y si está cerca, dos veces. Cuenta todo el ganado; porque en esto, no se puede fiar de los indios, que hay muchos fraudes en ello. Considera el multiplico de terneras, cotejado con el del año antecedente, y con el gasto del pueblo. Si ve que puede dar una buena ración cada día, sin que este gasto, junto con los avíos de los viajes, consumo de los estancieros, o pastores, etc. sea mayor que el multiplico anual, la da. (...) Las vacas no es finca que se venda, porque no hay para vender, excepto aquellos dos pueblos Yapeyú y San Miguel (...). (Cardiel, 2002).

Los indios estancieros vivían con sus familias en los puestos. La presencia de las mujeres y los niños ampliaba la cantidad de trabajo disponible. Es conocida la importancia del trabajo de infantil en los sistemas agrarios pre-industriales. El jesuita Sepp aconsejaba que en tiempos de parición se pusieran "cuatro muchachos pequeños de cuidar en cada corral de los corderitos", y que se les utilizara como pastores tanto de ovejas como de sus crías pequeñas. Asimismo, recomendaba que durante la esquila otros tantos niños se ocuparan de recoger los recortes de lana y ponerlos en sacos aparte del vellón (Sepp, 1985).

La permanencia de familias de guaraníes reducidos fuera de la aldea era un motivo de preocupación para los jesuitas, quienes temían una suerte de reversión a la vida "salvaje" si se dejaba a estos grupos durante mucho tiempo fuera de la vigilancia y de las rutinas férreas de la vida misional. En prevención, los puestos misioneros más poblados tuvieron una capilla consagrada y es posible que los jesuitas evitaran la concentración de cantidades importantes de población en los puestos. Hay indicios de que luego de la expulsión de los jesuitas en 1768 aumentó el número de puestos, y posiblemente haya aumentado también la población rural dentro del paisaje pastoril misionero. El inventario de los bienes del pueblo de Yapeyú en 1780 registró 23 puestos 
en el flanco oriental de su estancia y 18 del lado occidental. Mientras tanto, se habían formado dos poblados del lado occidental y uno del lado oriental, todos en torno a puestos antiguos (Maeder, 1981, p. 130). Uno de los administradores civiles que suplantaron a los jesuitas en 1785 dijo que era “(...) perjudicialísimo el crecido número de indios que hay en cada estancia, que con sus mujeres, muchachos y muchachas, regularmente pasan de 70 personas” (Gonzalo de Doblas, 1988). En 1801 el gobernador de Yapeyú informó que “(...) los naturales que residen en ellas [las estancias] tienen particularmente sus estanzuelas de ganado propios, y todas las familias, en general, tiene sus chacras, en las que suelen cosechar, para su manutención (...) maíz, mandioca, zapallos, y otros tanto frutos que produce el país". Así, puede suponerse que a comienzos del siglo XIX en algunos puestos de las estancias misioneras asomaba un proceso de "campesinización" de los guaraníes, posiblemente ligado a un contexto de progresivo descontrol de los antiguos rigores disciplinarios, una creciente ruralización de la población misionera y una mayor intensificación del trabajo comunal en las aldeas (Moraes, 2011).

\section{La cría de ganados mansos: Buenos Aires en la SEgunda Mitad deL Siglo XVIII}

La ganadería de Buenos Aires ha sido profusamente estudiada por numerosos autores de los últimos 30 años (Mayo, 1991, 2004; Pérez, 1996; Amaral, 1998; Garavaglia, 1999b). Se asentaba en unidades productivas que, aunque también se llamaban estancias, eran muy diferentes de las misioneras puesto que se trataba de fincas rurales de propiedad individual, de aproximadamente 2500 hectáreas, donde se criaban bovinos, bueyes, mulares y ovinos. Al principio las mulas eran un rubro productivo de primera importancia, junto con equinos y ovinos, y la producción bovina se hizo mayoritaria recién al final del siglo XVIII (Garavaglia, 1999a , p. 132).

En cuanto a la tecnología de la producción animal, en etapas tempranas se recurría al ganado bovino silvestre de las cercanías, pero numerosas fuentes indican que en el primer tercio del siglo XVIII las reservas cercanas se agotaron, lo que dio lugar a la lenta expansión del sistema de cría en rodeos “mansos" (domesticados) de aproximadamente 2500 cabezas (Garavaglia, 1999a , p. 206).

El principal mercado de la ganadería bovina bonaerense era el abasto de la ciudad. Hacia 1740 el consumo anual de carne era de unas 30.000 cabezas de vacunos, pero a fines del siglo rondaba las 46.000 y en la década de 1810 alcanzaba las 72.000 cabezas. Según los cálculos de Garavaglia, para una fecha entre 1788 y 1792 el consumo anual per cápita de Buenos Aires era de 193 kilos de carne vacuna (Garavaglia, 1999a , p. 218). Estos altos niveles de consumo tendieron a bajar al comenzar el siglo XIX, a medida que aumentaba el precio de la carne luego de la apertura del primer saladero en la Ensenada, en 1812. En cualquier caso, el mercado bonaerense de carne era suficientemente grande y dinámico para requerir un segmento criador estable y numeroso.

La producción ganadera de Buenos Aires se combinaba de diversas formas y proporciones con los cultivos, en una variedad de unidades productivas. Garavaglia identificó jefes de algunas unidades productivas familiares que calificó como pastores: modestísimos criadores que pastoreaban su rebaño en tierras ajenas mediante alguna forma de aparcería o por simple ocupación. Agrupados en familias nucleares, estos agentes se valían básicamente del trabajo familiar y formaban redes de parentesco o de paisanaje en parajes cercanos. Aunque su presencia era generalizada en la campaña de Buenos Aires, participaban con modestas cantidades en los mercados ganaderos y sus cultivos se destinan esencialmente al autoconsumo (Garavaglia, 1999a, pp. 300-301). Por otro lado, el ganado lechero y de tiro era un componente característico de las unidades productivas encabezadas por labradores, donde se plantaba trigo con base en el trabajo familiar (Garavaglia, 1999a, pp. 311-315).

Finalmente, en la cumbre del mundo social agrario estaba el grupo de los hacendados, una élite de grandes propietarios de ganado de diversas categorías, que a menudo eran también acopiadores de trigo y molineros. Utilizaban trabajo esclavo y libre, y producían tanto carne para el consumo de la ciudad como sebo y cueros, y 
mulas para la región minera. Aunque representan la cúspide de la estructura social rural, “(...) están lejos, muy lejos, de ser una casta feudal y demuestran tener una enorme capacidad y rapidez para adaptarse a los cambios impulsados por el mercado (...) (Garavaglia, 1999a , p. 327).

\section{De Cimarrones a mansos y VICEVERSA: EL SISTEMa gaNADERo MONTEVIDEANO}

La ganadería de Montevideo en la segunda mitad del siglo XVIII presentaba elementos técnicos tanto del paisaje bonaerense como del misionero. Estaba organizada en unidades productivas de propiedad individual, como en Buenos Aires, pero combinaba la cría con el arreo, como en las estancias comunales misioneras. En efecto, las estancias montevideanas eran fincas de propiedad individual; cada "suerte de estancia" tenía una superficie de 1992 hectáreas.

A juzgar por la información recogida de inventarios de chacras y estancias, los bovinos y los equinos mansos eran los pilares de la ganadería montevideana. A lo largo del siglo XVIII los bovinos mansos, que en 1756-1769 apenas eran la mitad del valor del stock animal de la jurisdicción de Montevideo, llegaron a ser el $85 \%$ del valor total del ganado al comenzar el siglo XIX. Tomando ese período en su conjunto, cerca del $45 \%$ de las unidades productivas rurales tenían bovinos de carne, un $47 \%$ tenía caballos, un $44 \%$ de los predios tenía bueyes, un 20\% tenía vacas lecheras y un 14\% del total tenía ovinos (Moraes, 2011).

En contraste, en los inventarios de las chacras y estancias de Montevideo no figuran los animales cimarrones. Por definición, el ganado "cimarrón" no tiene dueño, no ha sido marcado, y por eso mismo no es sorprendente que no figure en un inventario de bienes. En tal sentido, la fuente notarial sólo registra "vacas chúcaras" en los inventarios de 1760-1780, cuando se están "poblando" las estancias de la jurisdicción. Sin embargo, eso no debe inducir a creer que los cimarrones no jugaban ningún papel en la ganadería montevideana. Por un lado, las estancias montevideanas fueron formadas mediante el arreo de animales silvestres, como era la norma en el Litoral. La ocupación efectiva de la jurisdicción de Montevideo se logró después de 1751, cuando se alcanzó cierto statu quo con los pueblos originarios conocidos como minuanes. A partir de entonces se "normalizó" el proceso de ocupación del espacio montevideano y pudo hacerse efectiva la ocupación de algunas estancias ya concedidas, a la vez que se retomó la adjudicación de "suertes" en terrenos ahora conquistados efectivamente para el mundo colonial. En la década de 1760 las estancias montevideanas se extendieron hacia el noroeste (Pollero y Sagaseta, 2015 ). Los vecinos que recibían las concesiones tenían cinco años de plazo para poblar sus estancias con ganados; la práctica en ese momento era, como en toda la ganadería rioplatense, recoger ganado cimarrón y amansarlo para rodeos de cría de vacunos.

No hay estimaciones del rodeo animal en poder de los montevideanos con posterioridad a 1760, pero diversos indicios sugieren que el stock de bovinos de cría del paisaje montevideano difícilmente alcanzase las 100.000 cabezas durante todo el período, ya que con 70.000 se lograba satisfacer la demanda de carne de toda la población de la jurisdicción. Esta estaba formada por el consumo de los hogares y el consumo de la Real Hacienda, que compraba reses faenadas para alimentos de los presos de la cárcel, de las tropas militares de tierra y de los buques de la Armada Real que repostaban en el puerto regularmente desde 1779 (Moraes, 2011).

En contraste con Buenos Aires, donde el mercado del consumo urbano era un destino fundamental para la producción vacuna, la evidencia sobre Montevideo sugiere que allí la demanda originada en el consumo privado no era lo suficientemente grande para llevarla a su pleno potencial de producción. En consecuencia, en los períodos de sobreabundancia de ganado era una práctica generalizada entre los criadores dejar una porción del procreo sin herrar y permitir que volviera a su estado salvaje, fenómeno que los observadores europeos de la época denunciaron con horror como el colmo del desinterés por parte de los ganaderos. Esta situación empezó a cambiar en la década de 1780 con la apertura de los primeros establecimientos que elaboraban carne conservada en sal, llamados "saladeros" (Moraes, 2011). 
La carne en salmuera o carne salada era un método de conservación de la carne cruda en un caldo de sal que requería su empaque en toneles sellados; el tasajo o charque era carne también cruda, pero curada directamente con sal en grano y secada al aire libre. Ambos productos requerían numeroso personal a cargo de diversos procesos de cierto nivel de especialización: había que matar al animal en un redil, levantarlo con un sistema de poleas, desollarlo, trozarlo, deshuesar la carne y obtener las tiras o filetes de carne del tamaño adecuado. Luego había que cumplir los procesos de conservación: elaborar la salmuera en grandes tachos de cobre para la carne salada, poner los trozos en depósitos de sal en el caso del tasajo, envasar la carne salada en toneles, colgar a secar el tasajo en grandes tendales al aire libre. Por esta razón, estas fábricas de carne, que requerían abundante mano de obra a la vez que introducían una clara división del trabajo en el establecimiento, recurrieron al trabajo esclavo y constituyeron inversiones de cierto porte. En esta primera etapa de su historia, además, los saladeros de mayor tamaño eran empresas de integración vertical: para abastecer la demanda de un gran saladero de manera estable y fluida, los empresarios entendieron necesario incorporar la producción ganadera a la inversión. Por ejemplo, el plan de producción del primer saladero que se instaló en una región cercana a Colonia en 1780, incluía el mantenimiento de un rodeo de 30.000 cabezas vacunas para producir 8000 quintales por año de carne salada y tasajo. De este modo, el gran saladero era, a menudo, también una gran hacienda ganadera (Montoya, 1986: 121-139).

Las fábricas de carne salada se propagaron en los años siguientes en un número incierto dentro y fuera de la jurisdicción de Montevideo, por lo general como emprendimientos liderados por agentes vinculados al comercio de ultramar, pero también por algunos ganaderos de la zona de Colonia (Montoya, 1984; Barrios Pintos, 1967). En 1787 un montevideano decía:

En las inmediaciones de esta ciudad se han puesto otros dos [saladeros] que harán otros ocho mil [quintales de salazón] por año por año cada uno, y muchos particulares salan también en sus haciendas, porque los tres saladeros grandes se están disponiendo para empezar (Pérez Castellano, 1968, p. 22).

Se conoce una nómina de 36 empresarios que en las últimas décadas del período colonial invertían en el negocio del saladero en la orilla norte del Río de la Plata, ya sea en estancias de su propiedad o en establecimientos nuevos (Montoya, 1986, p. 307). La mayor parte de ellos eran navieros, comerciantes y contratistas del gobierno que también adquirieron grandes porciones de tierra.

El destino de las carnes manufacturadas era el mercado externo. Originalmente, los proyectos de fundación de saladeros apuntaron al abastecimiento de las tropas reales en España, pero el desarrollo del comercio con La Habana y con Río de Janeiro a partir de 1780, así como el aumento de la introducción de esclavos en aquellas economías durante 1790, pronto definió el destino de las carnes saladas. En efecto, en las últimas décadas del siglo XVIII Cuba estaba experimentando un proceso de expansión de la economía de plantación que, traspasando los límites originarios de la producción de azúcar, convirtió a la mano de obra esclava en la forma principal de trabajo de aquella economía. Esta expansión de la economía esclavista contó con la participación de agentes de las recientemente independizadas colonias inglesas de América del Norte. La red comercial con Cuba la tejió un grupo de comerciantes y empresarios navieros catalanes que por entonces comenzaba a afincarse en Montevideo y buscaba hacerse un lugar en la élite local. El primer embarque de carne salada a Cuba lo realizó un buque fletado por un patrón de buque catalán, que trajo a su regreso (a España) el barco cargado de azúcar y aguardiente. Muy pronto se desarrolló una ruta triangular que, partiendo de Montevideo, llevaba la carne salada a Cuba y seguía rumbo a Barcelona con aguardiente y azúcar. Las cantidades exportadas tendieron a aumentar cerca del final del siglo, desde embarques anuales del orden de los 35.000 quintales promedio en los primeros diez años de la industria, hasta unos 50.000 como promedio del período inmediatamente posterior (Silva, 1994).

No es fácil cuantificar el impacto de este modesto desarrollo sobre la ganadería montevideana. De una manera aproximada, puede decirse que el desarrollo de la industria de carne salada duplicó el tamaño del mercado formal del abasto montevideano, siendo casi igual al del consumo privado total (Moraes, 2011). Por 
lo tanto, puede decirse que la apertura de un mercado de ganado para los saladeros debe haber constituido un cambio radical para la ganadería de cría montevideana, en la medida que diversificó las oportunidades de colocación de los ganados y de exportación de productos pecuarios. Sin embargo, en los 30 años transcurridos desde que los primeros saladeros en la orilla norte del Río de la Plata y terminó el régimen colonial, las exportaciones de carne salada estuvieron expuestas a los vaivenes del tráfico de ultramar y en consecuencia el grado de desarrollo de la industria del tasajo se mantuvo en niveles muy modestos. La gran expansión de las exportaciones de tasajo por el puerto de Montevideo tuvo lugar después de las guerras de independencia (1810-1830).

\section{CAZAR Como Negocio: la “NUEVA ganadería del Cuero” (1780-1810)}

Aunque en el Río de la Plata siempre se habían exportado cueros bovinos, los volúmenes exportados crecieron a partir de la década de 1780, cuando se inició una suerte de boom exportador que, con fluctuaciones, duraba todavía cuando estallaron las guerras de independencia en 1810. Como se ve en el gráfico 1, las cantidades de cueros exportados legalmente aumentaron notablemente en la década de 1770 con respecto a la anterior, pero sobre todo dieron un salto en la década de 1780, cuando alcanzaron cifras promedio del orden de los 600.000 cueros anuales. Además del tráfico legal, se sabe que existía un tráfico ilegal de cueros, lo que significa que estas cifras son magnitudes de mínima, que, con certeza, eran mayores en una proporción que no se conoce con exactitud.

El "furor corambrero" no modificó la estructura de las exportaciones de la región platense, donde la plata siguió siendo el principal bien exportado. Pero impactó de manera importante sobre los sistemas ganaderos de la región y sobre los tres paisajes agrarios mencionados antes. Nació una economía del cuero novedosa en relación con el pasado, caracterizada por una producción de cueros a gran escala, que amplió el territorio de los sistemas ganaderos regionales y dio lugar a la gestación de nuevos agentes económicos y sociales, ligados a las actividades de producción masiva de cueros bovinos (Moraes, 2011).

La historiografía del siglo XX fue muy crítica de esta actividad, que identificó como la más primitiva de las etapas del desarrollo ganadero rioplatense. Denunció su carácter depredador de la riqueza animal y la asoció con una economía agraria de rasgos premodernos. Además, la ganadería del cuero fue denunciada como generadora de un tipo de hacendado acaparador de tierras y, en consecuencia, de unas estructuras agrarias fuertemente concentradas que perduran hasta el presente (Pivel Devoto, 1957; Barrán y Nahum, 1997; Sala et al., 1967).

\section{GRÁFICO 1}

Promedios anuales de la cantidad de cueros exportados legalmente por los puertos de Montevideo y Buenos Aires, 1756-1802

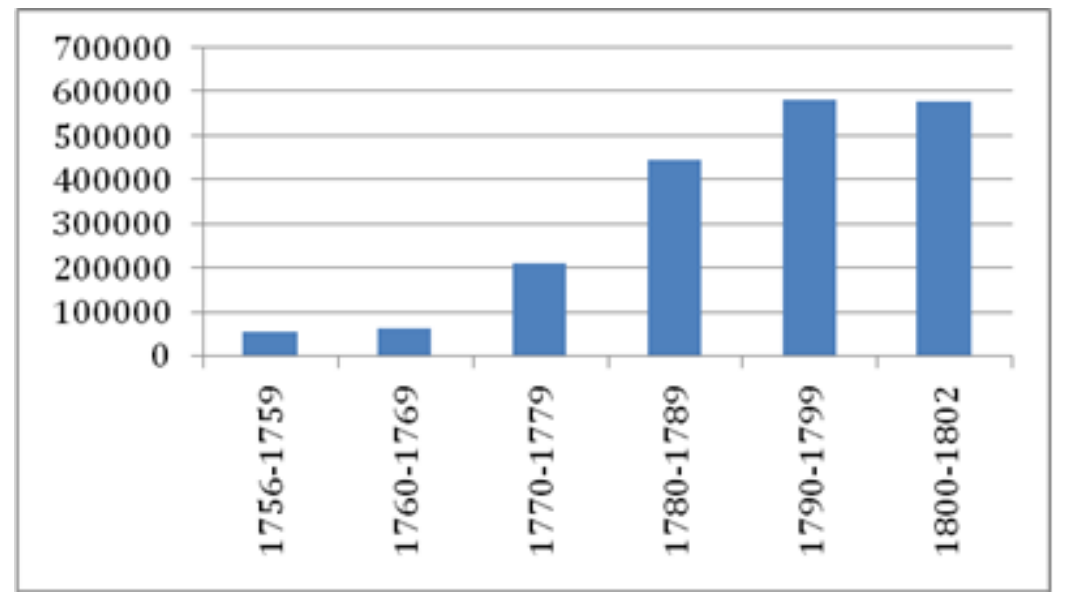


Fuente: Elaboración propia con la información de Pérez (1996, pp. 158-159)

Conviene, sin embargo, tener presente que la explotación del cuero durante esta etapa es una actividad pecuaria diferente de la ganadería de cría; se ejecuta sobre una base de ganados diferente y se obtienen productos también diferentes. La ganadería bovina de cría se hace con animales mansos; el producto principal es la carne (y eventualmente la leche), y el cuero es un subproducto. Los vientres (las vacas) son las categorías más importantes a los efectos de mantener el stock y los novillos son la categoría animal más cara, porque son el "producto final" del proceso. En cambio, la ganadería del cuero se hace con animales silvestres o cimarrones; el objetivo de la "faena de corambre" es la piel del animal, y la carne apenas un subproducto, en este caso de escaso valor, puesto que la ganadería de cría era más que suficiente para abastecer la demanda de alimentos. La ganadería del cuero en el Río de la Plata se basó en la explotación de los ganados silvestres, fue posible por su existencia y se desarrolló con vigor allí donde estos eran abundantes. No se hizo con los mismos animales ni en los mismos establecimientos que se practicaba la ganadería de cría. Cuando el boom exportador de cueros de las últimas tres décadas del dominio español se hizo sentir en las explotaciones rurales, los criadores seguramente obtuvieron con la venta de los cueros (un subproducto) un beneficio adicional, pero ningún criador mata un novillo gordo sólo para quitarle su piel. Esto explica por qué los estudiosos de la economía colonial tardía no han podido hallar ningún impacto del boom exportador de cueros en el precio de los bovinos mansos de Buenos Aires (Garavaglia, 1995; Cuesta, 2009) ni de Montevideo (Moraes, 2011). No es extraño, por lo tanto, que esta nueva economía del cuero acabara por desatar un conflicto entre agentes diversos de toda la región, por el control de los ganados silvestres, hasta entonces un tipo de animal cuya abundancia era tal que no despertaba la codicia de nadie.

La base microeconómica de estas transformaciones fue la "vaquería de corambre", una forma de explotación ganadera muy antigua, que vio modificado su papel. Se practicaba en el Río de la Plata desde tiempos remotos como una forma de aprovechamiento de los vacunos no sometidos a rodeo. Consistía en una incursión de una cuadrilla de hombres a caballo en territorios a menudo alejados de los pueblos y donde los bovinos salvajes eran abundantes, para encerrarlos, desjarretarlos y desollarlos. Con esta misma estructura técnica se llevó a cabo después de 1770 la intensa actividad de producción de cuero que dio sustento a los volúmenes exportados por los puertos rioplatenses. Los campos de Montevideo, las antiguas estancias misioneras y todo el territorio rioplatense fronterizo con el imperio portugués fueron el escenario de esta nueva economía. La campaña de Buenos Aires, donde los ganados silvestres se habían extinguido desde hacía décadas, no se vio afectada por ella. Los capitalistas de Buenos Aires participaron del negocio, en cualquier caso, tanto como hacendados del otro lado del Río, como en su rol de comerciantes exportadores.

Numerosos funcionarios públicos de la época advirtieron sobre los abusos que se cometían en las faenas de ganados sin marca y sobre la inmensa dificultad de las instituciones de gobierno para ejercer alguna clase de control sobre estas matanzas. La matanza de vacas fue objeto de preocupación real desde 1751, cuando Fernando VI expidió una Real Cédula que ponía pena de "perdimiento de bienes" a quienes la practicasen. La reiteración periódica de esta prohibición por parte de las autoridades provinciales/virreinales en 1752, 1753, 1755, 1775, 1779, 1790, 1791 y 1792 revela que la práctica continuaba (Barba, 1955 , p. 278). Del mismo modo, las autoridades ensayaron sin mayor éxito diversos mecanismos de control de los cueros producidos con estos animales sin herrar, llamados "cueros orejanos" (Pivel Devoto, 1957, p. 104). La Hacienda Real estaba interesada no sólo en preservar las reservas ganaderas, sino también en recaudar impuestos sobre una actividad que, aunque no era nueva, había alcanzado proporciones novedosas y generaba ganancias mayores. Una trama de intereses contrapuestos se generó en torno a la economía del cuero. Además de los intereses de la Corona, diversos agentes privados estaban interesados cada cual en su negocio: los comerciantes de Montevideo y Buenos Aires, que compraban los cueros para venderlos en los puertos europeos; los empresarios corambreros, que financiaban las cuadrillas que salían al campo a recoger animales silvestres; y hasta el personal subalterno empleado en estas cuadrillas. Finalmente, los cabildos de los pueblos misioneros, de Montevideo y de Buenos Aires, en tanto que titulares legítimos de los ganados silvestres, fueron actores 
protagónicos de una serie de conflictos legales por el aprovechamiento de los animales, ocurridos entre 1780 y 1810.

CUADRO 1

La división del trabajo en una vaquería de corambre último cuarto del siglo XVIII

\begin{tabular}{|c|c|c|}
\hline $\begin{array}{c}\text { Categoría } \\
\text { ocupacional }\end{array}$ & Tarea & $\begin{array}{c}\text { Forma de } \\
\text { remuneración }\end{array}$ \\
\hline Vaquero/Desjarretador & $\begin{array}{c}\text { Desjarreta y acodilla } \\
\text { el animal }\end{array}$ & destajo \\
\hline Peón desollador & $\begin{array}{c}\text { Despelleja al animal } \\
\text { y estaquea el cuero }\end{array}$ & $\begin{array}{c}\text { Recoge, limpia, } \\
\text { clasifica y apila los } \\
\text { cueros }\end{array}$ \\
\hline Barraquero & $\begin{array}{c}\text { Destajo o salario, } \\
\text { según los casos }\end{array}$ \\
\hline Sebero & $\begin{array}{c}\text { Extrae la grasa y } \\
\text { elabora sebo en } \\
\text { marquetas }\end{array}$ & mensual \\
\hline Peón caballerizo & $\begin{array}{c}\text { Cuida los caballos } \\
\text { de la cuadrilla }\end{array}$ & mensual \\
\hline
\end{tabular}

Fuentes: Elaboración propia a partir de Saguier (1991, 114 y 117) y Pérez

$(1996,152)$. Los datos de remuneraciones corresponden a los años 1772-1775.

Teóricamente, la vaquería era una actividad estacional; los meses de faena de corambre eran los meses de mayo, junio y julio, por estar los campos libres de cardos y estar lejos la fecha de las pariciones (Saguier, 1991 , p. 122). Pero este carácter estacional no era rígido: en algunos casos las vaquerías se prolongaban hasta el verano, y esta estación era la preferida por quienes incursionaban ilegalmente en la actividad, justamente para evitar cruzarse con las cuadrillas legales (Saguier, 1991, p. 122; Pérez, 1996 , p. 172-173). Estas cuadrillas de hombres contaban con una rigurosa división del trabajo, como se aprecia en el Cuadro 1: los peones desolladores eran las figuras principales y mejor remuneradas, seguidos de los desjarretadores, encargados de enlazar y matar el animal, pero había también peones específicamente encargados de las cabalgaduras y otros llamados "barraqueros", encargados de acondicionar y trasportar los cueros durante la itinerancia del equipo, que duraba meses.

El empresario que organizaba la cuadrilla daba a sus integrantes los instrumentos para desjarretar, acodillar y desollar a los animales, pero no los caballos, que debían ser provistos por los propios involucrados (Saguier, 1991 , p. 117). Además, corría a cargo del empresario la provisión de tabaco y yerba para los trabajadores (Saguier, 1991, p. 120), un complemento salarial imprescindible en todos los paisajes agrarios del Río de la Plata.

Los cueros obtenidos en las vaquerías debían llegar a los puertos para ser exportados. Los circuitos del cuero de este período han sido analizados recientemente (Biangardi, 2014, 2015). Los resultados obtenidos muestran que el negocio del cuero no se limitaba a meramente acopiar y vender; implicaba adelantar sumas importantes de capital y entrañaba una lógica empresarial inclinada a especular con los precios y las ganancias esperadas.

El más afectado de los paisajes agrarios rioplatenses fue el pastoril misionero. Después de 1770 el pueblo de Yapeyú se convirtió en un polo productor de cueros, con dos núcleos de operaciones fijas de caza de animales, 
desde donde se cubrían territorios adyacentes y se hacían esporádicas expediciones volantes a lo largo y a lo ancho de su vasta estancia (Sarreal, 2011 y 2014). El pueblo de San Miguel lo secundó en la producción de cueros, y todo el espacio ganadero de las misiones, caracterizado precisamente por la abundancia de su stock silvestre, empezó a ser perforado por agentes tanto castellanos como portugueses que codiciaban sus animales (Moraes, 2011 ). Los pueblos misioneros acabarían por ser los grandes perdedores del proceso, puesto que sus ganados y pastos comunales fueron objeto de una verdadera avanzada privatizadora que empezó en la década de 1780, estaba en pleno despliegue cuando llegó el fin del dominio colonial y se prolongó durante las guerras de independencia. Desde 1780 los derechos de propiedad comunal de los guaraníes de las misiones fueron seriamente cuestionados por grupos privados y por algunos funcionarios reales que coincidían en su preferencia por la propiedad individual (Moraes, 2015b). Después de las guerras de independencia, el cambio de estatus jurídico de las poblaciones nativas junto al despliegue de una legislación privatizadora de cuño liberal, que fueron fenómenos característicos de las nuevas repúblicas sudamericanas en el siglo XIX, acabaron por consolidar el despojo. En contraste, fueron los grandes hacendados de Montevideo, del Alto Plata y de la capitanía de Rio Grande do Sul los agentes que finalmente terminaron por controlar los disputados recursos.

\section{Conclusiones}

La producción ganadera de estos paisajes rioplatenses constituye sin dudas su rasgo más original, y de hecho llamó la atención de los observadores de todo tiempo y lugar. Sin embargo, siempre ha resultado difícil comprender la complejidad intrínseca de unos sistemas ganaderos en los que convivía la cría de animales domésticos con la explotación de animales silvestres de la misma especie. La historiografía tradicional tendió a ordenar estas realidades, aparentemente excluyentes la una de la otra, en una secuencia evolutiva en la cual la explotación de ganados cimarrones señalaba las etapas más primitivas y la cría-engorde bajo control humano indicaba las más avanzadas. Este trabajo ha mostrado que, tomando los tres paisajes en conjunto, es posible decir que, durante todo el período, y aún al cabo del mismo, la ganadería de cría sólo se había separado completamente de la explotación de animales silvestres en la campaña pampeana de Buenos Aires, conformada por los seis partidos más cercanos a la ciudad. En efecto, a juzgar por el copioso caudal de conocimiento acumulado sobre aquellos partidos, en la segunda mitad del siglo XVIII la cría de ganados estaba del todo autonomizada de la presencia de stocks cimarrones que abundaban en los campos del otro lado del Río de la Plata y de la desembocadura del Paraná. Pero no pasaba lo mismo en los paisajes montevideano y pastoril misionero.

En Montevideo, las fuentes mostraron que los ganados cimarrones no sólo fueron la base de la formación de planteles de animales mansos para poblar las estancias recién repartidas — un proceso que en la década de 1760 todavía estaba en curso - sino también que la ganadería de cría de la jurisdicción montevideana, al menos hasta 1780, recurría de manera intermitente a las reservas de cimarrones para reponer inventarios. Paradojalmente, esto no ocurría porque la capacidad reproductiva de los planteles mansos fuera insuficiente para atender la demanda final de carne, sino porque en contextos de sobre-oferta los procreos se dejaban sin marcar y sin amansar. De este modo, parecería que la cría ganadera de la campaña montevideana se movía entre períodos de sobreoferta y períodos de escasez que repercutían en el stock cimarrón: en situaciones de exceso de oferta de animales mansos el stock cimarrón aumentaba, y a la inversa, disminuía en situaciones de insuficiencia de mansos. Se trata, por lo tanto, de una ganadería de cría peculiar, que cuenta con la reserva de cimarrones para resolver sus desequilibrios de corto plazo. Aunque es posible que después de la apertura del primer saladero se hayan creado mejores condiciones para estabilizar la tasa de inversión en la ganadería de cría montevideana, la evidencia disponible permite saber que cuando estalló la Revolución de Mayo todavía el proceso estaba en curso.

En el paisaje pastoril misionero, por otro lado, el sistema ganadero de producción de carnes se abastecía explícitamente de unas reservas de cimarrones que los pueblos siempre reportaron en sus inventarios como 
propios. La evidencia disponible sugiere que la producción de carne vacuna para el abasto a los pueblos se apoyaba simultáneamente en el arreo y amansamiento de animales silvestres, por un lado, y en la reproducción dirigida de animales mansos por el otro. Esta peculiar combinación de arreo y de cría en el sistema ganadero misionero se explica porque los pueblos misioneros tuvieron desde el siglo XVII acceso ilimitado a reservas cuantiosas de animales silvestres que ambulaban dentro de sus extensas "estancias".

Finalmente, el notable aumento de la producción de cueros que tuvo lugar en uno y otro paisaje en las décadas finales del período se basó en la disponibilidad de "cimarrones", disponibilidad que, por cierto, debe haber tendido a la baja conforme se acentuaba su explotación, pero no había llegado a cero al final del período. Así, después de 1780, tanto en el paisaje montevideano como en el pastoril misionero eran visibles dos tipos de práctica ganadera, de las cuales, lejos de estar en retirada, la caza del ganado silvestre para obtener las pieles y, eventualmente la grasa, experimentaba un verdadero apogeo. En otros trabajos se mostró que la producción de cueros de los ganados cimarrones se convirtió en una actividad económica de primera importancia después de 1770 , una nueva economía del cuero en torno a la cual giraban capitales de porte y tasas de beneficio que podían alcanzar un porcentaje muy alto del capital invertido. También se mostró que las "vaquerías de corambre" eran una forma de organización de la producción de cueros vacunos caracterizada por la presencia de trabajo altamente especializado y remunerado (Moraes, 2011). Fue en ese marco de acelerada mercantilización de la ganadería que numerosos agentes se arrojaron sobre los cimarrones y la caza indiscriminada de animales silvestres generó preocupación. Pero la "vaquería de corambre" no era una actividad intrínsecamente depredadora: lo que puso en peligro la sustentabilidad del stock animal no fue la práctica de matar a los vacunos salvajes para tomarles la piel, sino la conjunción de un sistema mixto de derechos de propiedad, un agudizado conflicto entre agentes diversos por unos mismos recursos y una coyuntura comercial singular que valorizaba los ganados cimarrones.

En efecto, en las praderas rioplatenses convivían los derechos comunales sobre los ganados con los derechos individuales y los del Rey. Mientras el estado del comercio atlántico no alentó la formación de un mercado atractivo para los cueros, ni el Rey ni los particulares expresaron dificultades para reconocer los derechos de los pueblos misioneros sobre los animales cimarrones vivos. Pero cuando la coyuntura comercial se hizo favorable a las exportaciones de cueros y lo que hasta entonces era un recurso ocioso se convirtió en una mercancía, los agentes rivales cuestionaron hasta el derecho de los misioneros sobre los animales muertos. Así, fue la confrontación de intereses por unos mismos recursos —en vez de un supuesto rezago tecnológico - lo que acabó por desposeerlos de sus ganados y sus pastos.

La tecnología ganadera del Río de la Plata desde sus etapas tempranas hasta comenzar el siglo XIX no se ordenó en una secuencia progresiva de etapas tecnológicas, sino que respondió al desarrollo y comportamiento de los mercados, de los diversos agentes involucrados en el negocio ganadero y de los regímenes de propiedad vigentes en las diversas comunidades del territorio.

\section{REFERENCIAS}

Amaral, S. (1998). The rise of capitalism on the Pampas: the estancias of Buenos Aires, 1785-1870. Cambridge University Press.

Barba, E. (1955). Contribución documental sobre la historia de la ganadería en el Río de la Plata al finalizar el siglo XVIII. Revista Histórica XXIII, Nº 67-69: 264-336).

Barrán, J. P. y Nahum, B. (1978). Historia Rural del Uruguay Moderno. Tomo VII. Montevideo: Banda Oriental.

Barrán, J. y Nahum, B. (1997 [1964]). Bases económicas de la revolución artiguista. Montevideo: Banda Oriental.

Barrios Pintos, A. (1967). De las vaquerías al alambrado. Montevideo: Ediciones del Nuevo Mundo.

Bernhard, G. (1958). Comercio de carnes en el Uruguay. Montevideo: Aguilar Irazábal. 
María Inés Moraes. CaZadores y PaStores: agentes, mercados y Derechos de Propiedad en la ganaderí...

Biangardi, N. (2014). Faenados a contravención. Decomisos de cueros en la Banda Oriental durante 1784y 1785. En: Sandrin, M.y Biangardi, N. (comps). Los espaciosportuarios. Un lugar de encuentro entre disciplinas. (pp. 251-267) La Plata: Universidad Nacional de La Plata.

Biangardi, N. (2015). Expansión territorial, producción ganadera y relaciones de poder en la región Río de la Plata. Montevideo y Maldonado a fines del siglo XVIII (Tesis de doctorado, Universidad de la Plata).

Cardiel, J. (2002 [1770]). Breve relación de las Misiones del Paraguay. Colección Crónicas de América, Vol. 48. Madrid: Dastin.

Coni, E. (1979). Historia de las vaquerías del Rio de la Plata. Buenos Aires: Librería Platero.

Cuesta, E. M. (2009). Precios, población, impuestos y producción: la economía de Buenos Aires en el siglo XVIII. Buenos Aires: Temas Grupo Editorial.

Djenderedjian, J. C. (2004). ¿Un aire de familia? Producción ganadera y sociedad en perspectiva comparada: las fronteras rioplatenses a inicios del siglo XIX. Jahrbuch für Geschichte Lateinamerikas, 41(1), 247-274.

Doblas, G. (1988). Memoria histórica, geográfica, politica y económica sobre la provincia de Misiones. Montevideo: Ediciones de la Plaza.

Galaty, J. G. (2015). Pastoralism in Anthropology. En J. D. Wright (Ed.), International Encyclopedia of the Social \& Behavioral Sciences (pp. 577-583). Amsterdam: Elsevier, (Second Edition)

Garavaglia, J. C. (1975). Las actividades agropecuarias en el marco de la vida económica del pueblo de indios de Nuestra Señora de los Santos Reyes Magos de Yapeyú: 1768-1806. En E. Florescano (Coord.). Haciendas, Latifundios y Plantaciones en América Latina (pp. 464-492). México D. F.: Siglo 21.

Garavaglia, J. C. (1989). Ecosistemas y tecnología agraria: elementos para una historia social de los ecosistemas agrarios rioplatenses (1700-1830). Desarrollo Económico, 549-575.

Garavaglia, J. C. (1995). Precios de los productos rurales y precios de la tierra en la campaña de Buenos Aires: 1750-1826. Boletin del Instituto de Historia Argentina y Americana Dr. Emilio Ravignani, 11, 65-112.

Garavaglia, J. C. (1999a). Pastores y labradores de Buenos Aires. Buenos Aires: Ediciones de la Flor.

Garavaglia, J. C. (1999b). Un siglo de estancias en la campaña de Buenos Aires: 1751 a 1853. Hispanic American Historical Review, 79(4), 703-734.

Giberti, H. (1985). Historia económica de la ganadería argentina. Buenos Aires: Hyspamerica.

Ingold, Tim (1980). Hunters, Pastoralists and Ranchers. Reindeer Economies and Their Transformations. New York: Cambridge University Press

Ingold, Tim (1986). Reindeer Economies: And the Origins of Pastoralism. Anthropology Today, 2(4), 5-10.

La Salvia, Fernando (1988). "Remanescentes das atividades agro-pastoris dentro do espaço missioneiro". Ponencia presentada en el VII Simposio Nacional de Estudos Missioneros, Santa Rosa - Rio Grande do Sul.

Mayo, C. A. (1991). Landed but not powerful: the colonial estancieros of Buenos Aires (1750-1810). The Hispanic American Historical Review, 71(4), 761-779.

Mayo, C. A. (2004). Estancia y sociedad en la pampa, 1740-1820. Biblos.

Maeder, E. (1981) Historia económica de Corrientes en el período virreinal 1776-1810. Buenos Aires: Academia Nacional de la Historia.

Millot, J. Bertino, M. (1991). Historia económica del Uruguayomo I. Fundación de Cultura Universitaria

Miñarro, F. O., Martínez Ortiz, U., Bilenca, D. N. y Olmos, F. (2008). Río de la Plata Grasslands or Pampas \& Campos (Argentina, Uruguay and Brazil). En: A. Michelson (edit.): Temperate grasslands of South America, World Temperate Grasslands Conservation Initiative Workshop, Hohot-China, 24-33.

Menegat, C. (2016). "Transportando fortunas para povoar deserta e inculta campanha”: brasileiros e produção pecuária no norte do Uruguai em meados do Século XIX (Tesis doctoral). , PPG História - UFRGS.Porto Alegre, Brasil.

Montoya, A. (1984). Cómo evolucionó la ganadería en la época del virreinato. Buenos Aires: Plus Ultra.

Moraes, M. I. (2008). La pradera perdida: historia y economia del agro uruguayo: una visión de largo plazo, 1760-1970. Montevideo: Linardi y Risso. 
Moraes, M. I. (2011). Las economias agrarias del Litoral rioplatense en la segunda mitad del siglo XVIII: paisajes y desempeño (Tesis doctoral)., Universidad Complutense de Madrid, Madrid, España.

Moraes, M. I. (2015a). Antes de Artigas: economías agrarias en la "bada norte" del Río de la Plata. En G. Caetano y A. Ribeiro (Ed.). Tierras, reglamento y revolución. Reflexiones a doscientos años del reglamento artiguista de 1815 (pp. 457-486).

Moraes, M. I. (2015b). Introducción. En El arreglo de los campos. Montevideo: Ministerio de Educación y Cultura. Colección Clásicos Uruguayos, Vol. 199.

Pérez Castellano, J. M. (1968). Crónicas históricas. Montevideo: Ministerio de Cultura. Colección Clásicos Uruguayos.

Pérez, O. (1996). Tipos de producción ganadera en el Río de la Plata Colonial. La estancia de alzados. En E. Azcuy Ameghino et al. Poder terrateniente, relaciones de producción y orden colonial (pp. 151-184). Buenos Aires: Fernando García Cambeiro.

Pivel Devoto, E. (1957). Raíces coloniales de la revolución oriental de 1811. Montevideo: Editorial Medina.

Pollero, R. y Sagaseta, G. (2015). La aplicación del sistema de información georreferenciada al análisis de la Jurisdicción de Montevideo. Ponencia en VI Jornadas Uruguayas de Historia Económica, Simposio 16: Sistemas de Información Geográfica (SIG) en historia económica. Montevideo.

Ruano Fournier, A. (1936). Estudio económico de la producción de carnes del Río de la Plata. Montevideo: Peña y Compañía Impresores.

Saguier, E. (1991). El mercado del cuero y su rol como fuente alternativa de empleo. El caso del trabajo a destajo en las vaquerías de la Banda Oriental. Revista de Historia Económica IX, N 1, 103-126.

Sala, L., Rodríguez, J. y de la Torre, N. (1967). Estructura económica de la Banda Oriental. Montevideo: Ediciones Pueblos Unidos.

Sarreal, J. (2011). Disorder, Wild Cattle, and a New Role for the Missions: The Banda Oriental, 1776-1786. The Americas, 67(4), 517-545.

Sarreal, J. (2014). The Guarani and their missions: a socioeconomic history. Stanford: Stanford University Press.

Sepp, Antonio S. J. (1985 [1732]). Algunas advertencias tocantes al govierno temporal de los pueblos en sus fábricas, sementeras, estancias y otras faenas. En M. Bernardi (Ed.). Obras Completas de Mansueto Bernardi (pp. 29-43). Porto Alegre: Escola Superior de Teologia Sâo Lorenço de Brindes.

Silva, H. A. (1994). La estructuración del comercio y la navegación desde el Río de la Plata a Cuba. Anuario de Estudios Americanos, 51(2), 61-73.

Soriano, A. (1991). Río de la Plata Grasslands. En: R. Coupland, (Ed.). Ecosystems of the World. Natural Grasslands. Introduction and Western Hemisphere (367-407). Amsterdam: Elsevier.

Vázquez Franco, Guillermo (1986). Economia y sociedad en el latifundio colonial. Montevideo: Forum Gráfica Editora. Colección Hernandarias.

\section{Notas}

* La Agencia Nacional de Investigación e Innovación (Uruguay) financió el proyecto Historia de los mercados en el Río de la Plata (Fondo Clemente Estable) y la Comisión Sectorial de Investigación Científica de la Universidad de la República financió el proyecto Caracterización sociodemográfica y económica de las sociedades preindustriales de la Cuenca del Uruguay (Programa I+D). Ver también: http://pueblosynumeros.fcs.edu.uy/

\section{BY-NC-SA}

